\title{
SONS OR DAUGHTERS? SEX PREFERENCES AND THE REVERSAL OF THE GENDER EDUCATIONAL GAP*
}

\author{
Moshe Hazan \\ Tel-Aviv University and CEPR, Israel \\ HOSNY ZOABI \\ The New Economic School, Moscow, Russia
}

\begin{abstract}
We provide a new explanation for the narrowing and reversal of the gender education gap. We assume that parents maximize the full income of their children and that males have an additional income, independently of education. This additional income biases preferences toward sons and implies that females have relative advantage in producing income through education. When the returns to human capital are low, the bias toward sons is high, so that parents whose first newborns are females have more children. Consequently, daughters are born to larger families and hence receive less education. As returns to human capital increase, gender differences in producing income diminish, bias toward sons declines, variation in family size falls and the positive correlation between family size and the number of daughters is weakened. Ultimately, the relative advantage of females in education dominates differences in family size, triggering the reversal in the gender education gap.
\end{abstract}

Keywords: gender educational gap, fertility, returns to human capital

JEL Classification Numbers: I21, O11, J13

\section{INTRODUCTION}

Two salient features of development are the decline in fertility and the rise in education. These features have been widely discussed in the growth literature. ${ }^{1}$ This literature, however, has ignored the effect of gender differences on fertility and education decisions. ${ }^{2}$

Gender differences in education is a topic that attracts a lot of attention. In 2000, with the ambitious objective of ending world poverty, world leaders set eight "millennium development goals", one of which is to promote gender equality and empower women. One of the targets is to eliminate the gender disparity in primary

\footnotetext{
* We thank the editor and three anonymous referees for helpful comments. Hazan: Eitan Berglas School of Economics, Tel Aviv University, P.O. Box 39040, Tel Aviv 69978, Israel. E-mail: moshehaz@ post.tau.ac.il. Zoabi: The New Economic School, Nakhimovsky Prospekt, 47, Moscow 117418, Russian Federation. E-mail: hosny.zoabi@ gmail.com. Hazan greatly acknowledges financial support provided by the Falk Institute.
} 
and secondary education by 2005, and in all levels of education by 2015 . In 2010 , gender gaps in primary and secondary schools had narrowed in some developing regions, though large disparities remained at the university level. Nevertheless, in Oceania, sub-Saharan Africa, and Western Asia, large gaps remain even in primary education. ${ }^{3}$

Education for both genders began to rise during the 19th century. Initially females received less education, but the rise of females' education has been steeper, leading to a reversal in gender education gaps. Thus, while females' education has lagged behind males' until recently, today females' education surpasses males' in most developed economies. Goldin, Katz and Kuziemko (2006) analyzed 17 OECD countries with consistent tertiary schooling enrollment data for 1985 and 2002. They showed that while in 1985 only four countries had a ratio of male-tofemale undergraduates that was below one, by 2002 , women outnumbered men in higher education enrollment in 15 out of these 17 countries. This change is not confined to developed countries. Becker, Hubbard and Murphy (2010) showed that while in 1970 men's college attainment was higher than women's in almost all 120 countries in their sample, by 2010 women's college attainment surpassed men's in most rich countries and in about one-third of countries with per capita income below the median.

The increase in education has been accompanied by a decline in fertility in virtually all the regions of the world. Over the period 1960-1999, total fertility rate (TFR) plunged from 6 to 2.7 in Latin America, and from 6.14 to 3.14 in Asia. TFR in Western Europe and the Western offshoots, which began to decline in the 19th century and continued this trend over the period 1960-1999. In Western Europe over the same period TFR declined from 2.8 to 1.5, and in the Western offshoots from 3.84 to 1.83. Even in Africa, TFR declined moderately from 6.55 in 1960 to 5.0 in 1999 (Galor 2005).

In this paper, we argue that the reversal of the gender education gap and the decline in fertility are linked to parents' preferences for sons. These preferences are not exogenous, but evolve endogenously in response to the increase in demand for human capital. Our explanation emphasizes how uncertainty regarding the gender composition of the household affects the decision about family size and education level. We suggest that this uncertainty generates the gender education gap. Furthermore, the closing of the gender education gap and its reversal-a process accompanied by a decline in fertility-stems from the diminution of the importance of uncertainty as development progresses.

We extend a standard household decision model regarding the quantity (family size) and quality (education) of its offspring along two dimensions. ${ }^{4}$ First, we explicitly allow parents to value daughters and sons differently. Since the gender of each child is unknown ex ante, fertility becomes a choice under uncertainty. This uncertainty plays an important role in determining family size. Second, we model fertility choice as a sequential process, making parents' stopping rule, i.e. whether to have an additional child or not, depend on the current number and gender of children. ${ }^{5}$ 
We do not consider sex concerns as a taste phenomenon; economic costs and benefits associated with offspring's gender might affect parental choice. Although, many different determinants may affect parents' choice of family size and education investment, we limit our discussion to the extent that exogenous variables matter. These variables might be described by technology or discrimination and may change the returns to males' and females' labor over time. We assume that parents care about the full income of their children. This full income is the sum of income accrues to human capital, which depends on education and an additional income that accrues to each son but not to daughters. ${ }^{6}$ We assume that this additional income is the only difference between sons and daughters.

We attribute this additional income to differences in endowment between males and females. We focus on the noticeable difference between males and females in their physical strength. Pitt, Rosenzweig and Hassan (2012) present evidence on the distribution of grip strength among adult males and females in the U.S. and rural Bangladesh. Their Appendix Figure 1, shows that in both populations men are substantially stronger than women, and that the distributions by gender are similar in both countries. Thomas and Strauss (1997) showed that these differences are relevant for labor market earnings. They found that in urban Brazil, body mass contributed to males' earnings but not to females'. Finally, Bacolod and Blum (2010) found that physical strength is required even in (8\% of the) occupations of college graduates, implying that individuals supply their physical strength in combination with other skills including education.

Imagine an environment in which the returns to human capital are relatively low. In this environment, the additional income that accrues only to sons, is relatively large, and, therefore, parents value sons significantly more than daughters. Consequently, since the gender of a child is known only after the decision to have an additional child is taken, parents who obtain daughter(s) in their first birth(s) may have more children. Thus, uncertainty regarding children's gender induces higher realized fertility.

In contrast, imagine a different environment in which the returns to human capital are relatively high, and therefore, parents value sons and daughters (asymptotically) equally. Consequently, the uncertainty regarding the gender of a forthcoming child is irrelevant to fertility choice, and therefore, parents end up with lower fertility. Thus, we argue that part of the decline in fertility may be attributed to the diminishing role of uncertainty about a child's gender as development progresses. One testable prediction of this model, that distinguishes it from many of the models of the demographic transition, is that in our model the decline in fertility is accompanied by a decline in the coefficient of variation of household size. Notice that variation in family size arises only due to the gender of the children. That is, in our model, parents are ex ante identical but ex post end up with different realized fertility. A second testable prediction of our model is that on average, girls come from larger households than boys.

Recall that the additional income is the only difference between sons and daughters. In particular, we assume that the marginal cost and benefit of education 
are the same for both sexes. Hence, our third testable prediction is that the optimal education chosen by parents is independent of a child's gender. That is, within a household there are no differences in the education level of the children. Moreover, for a given family size, children's full income increases with the number of sons at each level of education. Since parents maximize the full income of their children, controlling for family size, parents with more sons optimally allocate less resources to children and more to their own consumption. Thus, our fourth testable prediction is that the optimal level of education decreases with the number of sons for households of the same family size.

Having said that, one might mistakenly conclude that males' education is lower than females'. Recall, however, that as discussed above, in an environment in which the returns to human capital are relatively low, parents value sons significantly more than daughters. Thus, parents who are "lucky" and obtain son(s) in the first birth(s) end up with smaller families, compared to parents who obtain daughter(s) in the first birth(s). Having a smaller family increases the resources that can be allocated to the quality of each child. Thus, in our model two effects work in opposite directions. On the one hand, on average, boys come from smaller families and, therefore, their level of education is higher. But, on the other hand, education level decreases with the number of sons for households of the same family size. It is, therefore, possible that the first effect dominates, leading to a situation in which the economy-wide average level of education of boys is higher than for girls.

In contrast, however, in an environment in which the returns to human capital are relatively high, parents value sons and daughters (asymptotically) equally. Consequently, the uncertainty regarding the gender of a forthcoming child is irrelevant to fertility choice, and all households are of the same size. ${ }^{7}$ In this situation, only the second effect is present: the optimal level of education decreases with the number of sons for all households, and, therefore, the economy-wide average level of education of boys must be lower than girls'.

The crucial element in our mechanism that drives the transition between the two environments described above is the increase in the relative returns to human capital. We attribute this increase to technological progress that has benefited brains more than brawn. This view gained much attention in the empirical literature, focusing on gender differences in labor market outcomes. Goldin (1990) shows that females' relative wage in manufacturing almost doubled in the 19th century America. She attributes much of this increase to the introduction of machinery that replaced strength and skills. For more contemporaneous periods, Bacolod and Blum (2010) estimated the returns to primary attributes such as cognitive skills and physical strength in the U.S. They found that between 1968 and 1990, the returns to cognitive skills, relative to physical strength, have increased. Bacolod and Blum (2010) also found that the fraction of occupations that requires physical strength decreases with education. ${ }^{8}$ Finally, Bacolod and Blum (2010) show that women are more concentrated in occupations that are intensive in cognitive skills, relative to men. The combination of these three findings is shown to account for $20 \%$ of the rise in women's relative wage over this period. 
Our first prediction that the coefficient of variation of family size decreases with development is consistent with U.S. data. Jones and Tertilt (2008) calculated the distribution of family size for cohorts of American women born between 1828 and 1958. As evident from their Figure A3, the variation of family size has been decreasing over this period.

There exists much empirical literature linking gender composition to family size and educational outcomes, covering a wide range of countries at different stages of their development process. In particular, our second prediction that on average, girls come from larger families than boys in early stages of development, has received much support. Jensen (2005) showed that this is the case in India, China, Egypt, Korea, Malaysia, Morocco, Nepal, Syria, and Turkey and Angrist et al. (2010) documented this fact for Israeli families who originate from Asia or Africa. ${ }^{9}$ To contrast this with evidence from a highly developed country, using the 1970, 1980, and 1990 U.S. census data, Ben-Porath and Welch (1976) and Angrist and Evans (1998) found that boys and girls come from the same family size. ${ }^{10}$

Our third prediction that at the household level, sons and daughters obtain the same level of education, has recently received attention in the development literature. Consistent with our model's predictions, Jensen (2005) found that in India there are large, clearly identifiable subgroups for which within-household estimates reveal no differences in education between boys and girls. He also found that because girls, on average, come from larger families, at the aggregate level, girls' education lags behind boys', as our model predicts. Moreover, Jensen (2005) concluded that between one-tenth and one-quarter of the large male-female differences in educational attainment can be accounted for by the differences in sibling cohort size. Recently, Haider and McGarry (2012) have utilized a rich U.S. longitudinal information in the Health and Retirement Study in order to examine theoretical predictions about the magnitude of parents' investments in children's education. Their results concerning schooling transfers are consistent with our model's predictions for the later stage of development. They write "...transfers to boys are lower than those to girls by about $\$ 720$, but this effect disappears in the family fixed effects version [...] these results imply that families with more boys transfer less for schooling [...] but that parents do not differentiate between sons and daughters within a family." (p. 25) ${ }^{11}$

There is much less evidence, however, regarding our fourth prediction that the level of education is decreasing in the number of sons, conditional on family size. Butcher and Case (1994) found that for white Americans born between 1921 and 1960, the gender composition has no effect on men, but among women, those who grew up with a sister obtained less education than those who grew up with a brother. In contrast, Kaestner (1997) found that for black teenagers and adults, those who grew up with a sister, or who had relatively more sisters, had higher levels of educational achievements than black teens or adults with no or fewer sisters.

Recently, several explanations for the reversal of the gender education gap have been offered in the literature. Chiappori, Iyigun and Weiss (2009) assumed that 
women suffer from statistical discrimination, which declines with education. This implies that women face higher returns to schooling in the labor market since education can serve as a mean to escape discrimination. As technology of home production improves, women spend less time at home and the returns to schooling in the labor market becomes the main determinant of schooling. At this stage a reversal in education may occur. Iyigun and Walsh (2007) argued that since men are in short supply in the marriage market women are induced to invest more than men in competition for the scarce males. Another explanation stems from the risks associated with divorce. Chiappori and Weiss (2007) showed that men are more likely to initiate divorce when couples face a poor quality of match, because of men's typically higher income and custody arrangements. As a result, women may insure themselves against unwanted divorce by investing more in schooling. Becker et al. (2010) argue that since girls have both higher average levels and smaller variances of non-cognitive abilities than boys do, the supply of female college graduates is more elastic than that of males. When the demand for college graduates is sufficiently high, women surpass men in college graduation. Finally, Pitt et al. (2012) and Rendall (2010) assume men and women are endowed with brains and brawn and that men have more brawn than women. In both models, sufficiently high returns to brains induce women to invest more in education. A clear distinction between our explanation and the literature, is the key element in triggering the reversal in education. While in our model it is the decline in the variation in family size, in the studies mentioned above it is the increase in women's participation in the labor market.

At a broader perspective, our paper belongs to the literature on the bi-directional relationship between women's empowerment and economic development. In her review of both sides of this relationship, Duflo (2011) argues that the interrelationships are probably too weak to be self-sustaining. This leads her to conclude that policy geared toward equality should be perused. Recent theoretical models challenge the relationship running from women's empowerment to development. Basu (2006) shows that investment in children is best achieved when power is evenly balanced between parents. Thus, Basu's mechanism suggests a non-monotonic relationship between women's empowerment and development. Similarly, Doepke and Tertilt (2011) present a series of models in which targeting transfers to women need not necessarily lead to higher investment in children. In contrast, the impact of development on women's status in society is well founded. In the labor market, much of the closing gender gap in wages and employment is attributed to the process of industrialization (Goldin 1990) and the invention of the pill enabled women to combine family life with professional careers similar to men (Goldin and Katz 2002). In the political arena, the increase in the returns to human capital has led men to voluntarily give women political rights (Doepke and Tertilt 2009). Our paper emphasizes the direction from development to empowerment.

The rest of the paper is organized as follows. In Section 2, we present the structure of the model, and in Section 3, we solve the optimization problem faced by a representative household. In Section 4, we analyze the aggregate behavior of 
the economy during the process of development. In Section 5, we present some concluding remarks. Most of the proofs are in the Appendix.

\section{THE MODEL}

Consider an adult who is endowed with $H_{p}$ units of human capital and one unit of time, which is allocated between child rearing and producing the consumption good. The adult's preferences are represented by the utility function

$$
u=\ln (c)+\ln \left(n_{f} I_{f}+n_{m} I_{m}\right),
$$

where $c$ is household's consumption, and $I_{f}$ and $I_{m}$ are the full income of each daughter and son respectively, upon becoming adults. $n_{f}$ and $n_{m}$ are the number of daughters and sons respectively, and we assume that $n_{f}$ and $n_{m} \in \mathbb{N}_{0}$.

The full income of each child, as she (he) becomes an adult female (male), is determined by her (his) human capital and an incremental income, $b$, that accrues only to males. Formally, the full income of females and males, $I_{f}$ and $I_{m}$, is then given by

$$
I_{f}=w H_{f}
$$

and,

$$
I_{m}=w H_{m}+b,
$$

where $w$ is the wage per one unit of human capital and $b>0$.

For simplicity, we assume that human capital is determined solely by the time parents allocate to education according to the production function

$$
H=h(e)=e^{\theta},
$$

where $e$ is parental time spent on education and $\theta \in(0,1)$. Notice that both, daughters and sons face the same production function. Furthermore, we assume that educational decisions are made after family size is realized.

Rearing children, irrespective of their education, also requires parental time. ${ }^{12}$ Let $\tau$ denote this time cost associated with each child, regardless of its gender. Thus, each parent spends $\tau n+n_{f} e_{f}+n_{m} e_{m}$ units of time on raising and educating children, with $n=n_{f}+n_{m}$ and $e_{f}$ and $e_{m}$ being the time allocated to the education of each daughter and son, respectively. The remaining time, $1-\left(\tau n+n_{f} e_{f}+\right.$ $\left.n_{m} e_{m}\right)$ is allocated to produce the final good. Thus, the budget constraint is given by

$$
c=\left[1-\left(\tau n+n_{f} e_{f}+n_{m} e_{m}\right)\right] w H_{p} .
$$

The household's objective is to maximize, in equation (1), subject to the constraints in equation (5), the human capital production function in equation (4) and the full income, given by equations (3) and (2). 
To emphasize the role uncertainty plays in parental choice, we depart from the literature by assuming that the parent chooses fertility sequentially. We assume that the probability of giving birth to a son or daughter is equal to $1 / 2$ and is independent across births. Since in general $I_{f}$ and $I_{m}$ need not be equal, the marginal utility from having a daughter differs from the marginal utility from having a son. Consequently, the decision to have an additional child may depend on the gender composition of the children already born. Note also that in doing so, the household takes into account its planned investment in the optimal education of each daughter or son. Thus, it will be convenient to describe the value function of the household as a function of the state variables, $n$ and $n_{m}$

$$
U\left(n, n_{m}\right)=\max \left\{V\left(n, n_{m}\right), \frac{1}{2} U\left(n+1, n_{m}\right)+\frac{1}{2} U\left(n+1, n_{m}+1\right)\right\},
$$

where

$$
V\left(n, n_{m}\right)=\ln \left[c\left(n, n_{m}\right)\right]+\ln \left[\left(n-n_{m}\right) w h\left(e_{f}\left(n, n_{m}\right)\right)+n_{m}\left(w h\left(e_{m}\left(n, n_{m}\right)\right)+b\right)\right],
$$

and $c\left(n, n_{m}\right), e_{f}\left(n, n_{m}\right)$ and $e_{m}\left(n, n_{m}\right)$ are the optimal consumption and educational level for the daughters and sons, respectively, for any given pair $\left(n, n_{m}\right)$. In the next section, we analyze the optimal educational level for the daughters and sons for a given pair of $\left(n, n_{m}\right)$, and then we analyze the optimal fertility choice.

\section{OPTIMIZATION}

We begin this section by analyzing the household's optimal educational choice for any pair of $\left(n, n_{m}\right)$. We then turn to the optimal fertility choice.

\subsection{The Optimal Education Choice}

Given $\left(n, n_{m}\right)$, and substituting equations (2)-(4) into the utility function, equation (1), the maximization problem becomes

$$
\begin{aligned}
& \operatorname{Max}_{e_{f}, e_{m}}\left\{\ln (c)+\ln \left(\left(n-n_{m}\right) w\left(e_{f}\right)^{\theta}+n_{m} w\left(e_{m}\right)^{\theta}+n_{m} b\right)\right\} \\
& \text { s.t. } \quad c=\left[1-\left(\tau n+\left(n-n_{m}\right) e_{f}+n_{m} e_{m}\right)\right] w H_{p},
\end{aligned}
$$

differentiating with respect to $e_{f}$ and $e_{m}$ we get

$$
\frac{\theta w\left(e_{f}\right)^{\theta-1}}{\left(n-n_{m}\right) w H_{f}+n_{m}\left(w H_{m}+b\right)}=\frac{1}{1-\left(\tau n+\left(n-n_{m}\right) e_{f}+n_{m} e_{m}\right)},
$$

and

$$
\frac{\theta w\left(e_{m}\right)^{\theta-1}}{\left(n-n_{m}\right) w H_{f}+n_{m}\left(w H_{m}+b\right)}=\frac{1}{1-\left(\tau n+\left(n-n_{m}\right) e_{f}+n_{m} e_{m}\right)} .
$$


Notice that equations (8) and (9) show that the optimal levels of education for both, daughters and sons depend on family size and the gender composition of the children, $\left(n, n_{m}\right)$. Formally, let $e_{f}=e_{f}\left(n, n_{m}\right)$ and $e_{m}=e_{m}\left(n, n_{m}\right)$ be the level of education of daughters and sons, respectively.

In case that $n-n_{m}>0$ and $n_{m}>0$, both equations (8) and (9) have to hold and equation (8) and (9) collapse to

$$
h^{\prime}\left(e_{f}\left(n, n_{m}\right)\right)=h^{\prime}\left(e_{m}\left(n, n_{m}\right)\right) .
$$

Equation (10) leads us to the following proposition:

Proposition 1. For a given number of children, households with both daughters and sons provide the same level of education to their offspring regardless of their gender: $e_{f}(n)=e_{m}(n)=e(n)$.

Proof. Follows immediately from equation (10).

The intuition behind this result is that the marginal cost of educating a child and the marginal contribution of education to the full income of the child are both independent of its gender. Thus, for households with both daughters and sons, $H_{f}=H_{m}=H$.

Next, we would like to understand how the gender composition of the children affects the optimal level of education for a given family size. Using the result in Proposition 1 in either equations (8) or (9) we get,

$$
\frac{\theta w e^{\theta-1}}{n w H+n_{m} b}=\frac{1}{1-(\tau+e) n} .
$$

For a given number of children, the left-hand-side of equation (11) represents the marginal utility from education, which decreases with the number of sons, while the right-hand-side of equation (11) represents the marginal cost of education, which is independent of the number of sons. This leads us to the following proposition:

Proposition 2. For a given number of children, the level of education is strictly decreasing in the number of sons in the household: $e\left(n, n_{m}\right)>e\left(n, n_{m}+1\right)$.

Proof. See the Appendix.

The intuition is the following: sons' income is higher than daughters', for any level of education. As a result, the marginal utility from children's full income decreases faster with sons, compared to daughters, causing the parent to allocate more resources to consumption at the expense of children.

Finally, for a given number of sons, the left-hand-side of equation (11) decreases with the number of children, while the right-hand-side of equation (11) increases with the number of children. This leads us to the following proposition:

Proposition 3. For a given number of sons, the level of education is strictly decreasing in the number of children in the household: $e\left(n, n_{m}\right)>e\left(n+1, n_{m}\right)$. 
Proof. See the Appendix.

The intuition is that larger families allocate less resources to each child. This is the standard quantity-quality tradeoff result (Becker and Lewis 1973).

Propositions 1 and 2 suggests that as long as fertility is unaffected by the gender of the children, on average, females' education outweighs males'. However, the analysis that follows shows that fertility is affected by the gender composition of the children, as long as the incremental income, $b$, generates a sufficiently high difference in the full income of daughters and sons.

\subsection{The Optimal Fertility Choice}

After analyzing the optimal level of education for a given family size and gender composition, we now turn to the determination of optimal fertility. Given that the marginal utility from children decreases faster with the number of sons than daughters, parents may find it optimal to stop giving births at a lower parity if they get more sons. Denoting the optimal fertility for a given number of sons by $n^{*}\left(n_{m}\right)$, we get the following proposition:

Proposition 4. The optimal level of fertility is non-increasing in the number of sons: $n^{*}\left(n_{m}\right) \geq n^{*}\left(n_{m}+1\right)$.

Proof. See the Appendix.

Proposition 4 states that family size may decrease with the number of sons. As explained above, this result stems from the fact that sons' full income is higher than daughters' and, thus, the marginal utility from children decreases faster with sons. The pace of this decrease in marginal utility depends on the importance of $b$ in producing income, relative to $H$. This, however, depends on the optimal level of education, which itself depends positively on the returns to human capital, $w$. Specifically, when $b$ is sufficiently large, relative to $w$, sons are valued much more than daughters, and therefore, parents who obtain more sons in the first birth(s) stop giving births at a lower parity. In contrast, when $b$ is sufficiently small, relative to $w$, sons and daughters are valued asymptotically equally, and therefore the stopping rule is independent of the gender composition. The following proposition summarizes this discussion:

Proposition 5. The optimal level of fertility is independent of the number of sons for a sufficiently high $w$.

Proof. See the Appendix.

\section{AGGREGATE BEHAVIOR OF THE ECONOMY AND THE PROCESS OF DEVELOPMENT}

In Section 3, we characterized the optimal fertility and education decisions of a representative household. In this section, we analyze the aggregate behavior of the economy during the process of development. 
Consider an economy, which consists of a continuum of measure one of adults who are ex ante identical. That is, all adults have the same preferences and possess the same level of human capital, $H_{p}$. Each adult forms a household and faces the optimization problem solved in Section 3. In what follows, we solve the model numerically. Specifically, for a given set of parameters, we obtain a discrete distribution of households who are ex post heterogeneous due to the gender composition of the children. For each type of household we obtain the optimal family size and the optimal level of education. We then compute the aggregate variables of the economy, namely average fertility and average education of female and male children. We then repeat this procedure, changing only the returns to human capital, $w$. Due to the complexity of the problem, we do not keep track of children born in some period $t$ and assume they turn adults in period $t+1$. Rather, we assume that in $t+1$ the economy is again populated with a continuum of measure one of adults who are ex ante identical. We note, however, that given the utility function we specified in Section 2, the optimal fertility and education choices are independent of adults' human capital. ${ }^{13}$ Thus, even if we had kept track of individuals, the differences in human capital of offspring would not have had any effect on their optimal choices as adults and, therefore, nor would there be any effect on aggregate behavior. ${ }^{14}$

Before we turn to the numerical solution, however, we would like to emphasize the forces that drive the aggregate behavior of the economy at different stages of development. We already understood from the optimal solution of the representative household that the number of sons in the household has an ambiguous effect on the optimal level of education. On the one hand, given family size, the number of sons negatively affects education, since the contribution of education to total income of offsprings is smaller the more sons a household has. On the other hand, the number of sons decreases the marginal utility from children faster, causing families with more sons to stop giving births at lower parities. In smaller families, in turn, there are more resources to be invested in the education of each child.

Formally, these two opposite economic forces are described by

$$
\begin{aligned}
{\left[e\left(n^{*}\left(n_{m}+1\right), n_{m}+1\right)-e\left(n^{*}\left(n_{m}\right), n_{m}\right)\right] } \\
=\left[e\left(n, n_{m}+1\right)-e\left(n, n_{m}\right)\right]+\left[e\left(n+1, n_{m}\right)-e\left(n, n_{m}\right)\right] \cdot\left[n^{*}\left(n_{m}+1\right)\right. \\
\left.\quad-n^{*}\left(n_{m}\right)\right] .
\end{aligned}
$$

If we think of $n$ and $n_{m}$ as continuous variables, equation (12) can be rewritten as:

$$
\frac{d e^{*}}{d n_{m}}=\frac{\partial e^{*}}{\partial n_{m}}+\frac{\partial e^{*}}{\partial n^{*}} \frac{\partial n^{*}}{\partial n_{m}} .
$$

The first term on the right-hand-side of equation (13) describes the first channel described above, which is negative, as established in Proposition 2. The second multiplicative term on the right-hand-side describes the second channel. This term comprises two elements, both of which are negative, yielding a positive effect. 


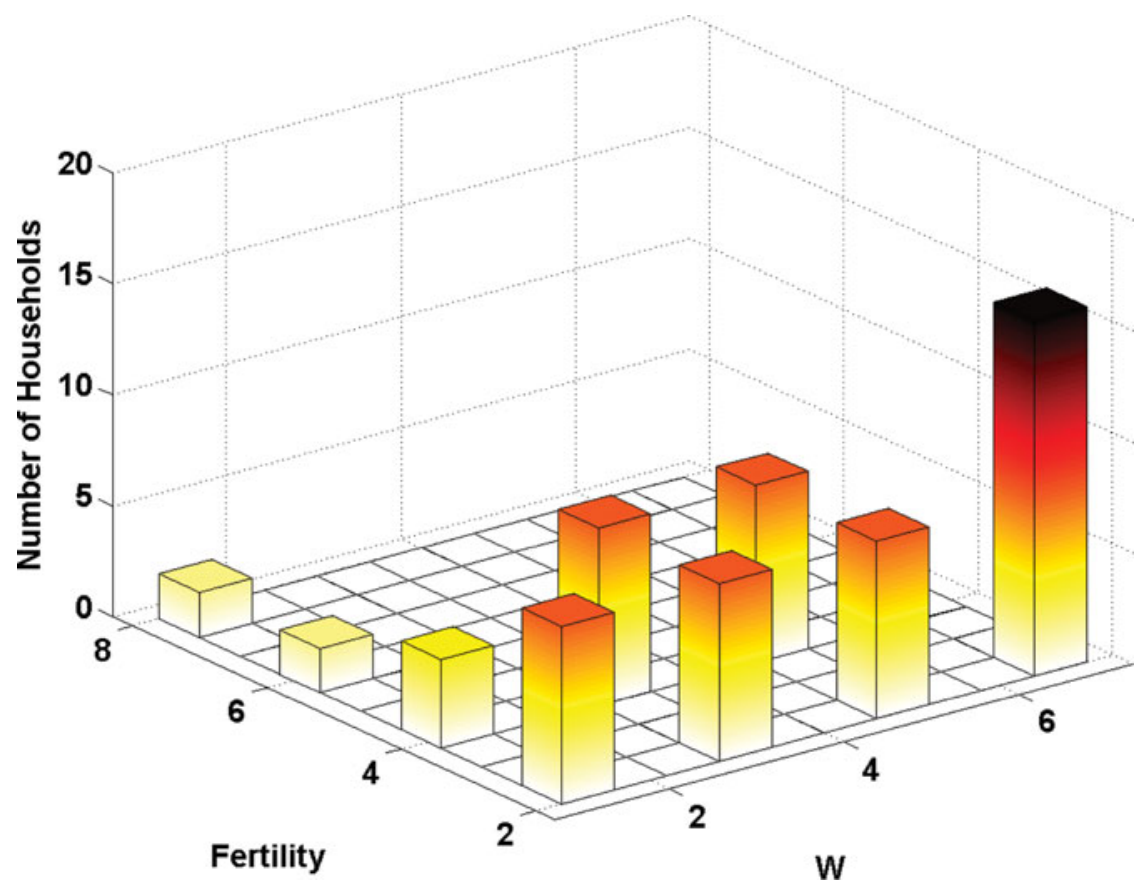

FIgURE 1. (Colour online) The evolution of the distribution of family size as a function of the returns to human capital, $w$; parameter values, $\tau=0.21, b=0.5$ and $\theta=0.5$.

The first element represents the standard quantity-quality tradeoff, as established in Proposition 3, while the second element represents dependency of family size on the gender composition of the children, as established in Proposition 4. While in principle the sum of these two terms can be negative or positive, we note that in Proposition 5 we established that family size becomes independent of the gender composition of the children as the returns to human capital approach infinity, and, therefore, the second term on the right-hand-side of equation (13) becomes zero. Thus, for sufficiently high returns to human capital, which represent advanced stages of development, females' average education must surpass males'. As we demonstrate below, however, for sufficiently low returns to human capital, which represent early stages of development, the second term dominates, suggesting that males' average education is higher than females.

Figure 1 exhibits a numerical example that shows the evolution of the distribution of family size during the process of development. It shows that when the returns to human capital are sufficiently low, household size varies from two to eight, depending on the gender of the children in the first births. As the returns to human capital increase, the variation in households' size decreases, reaching zero at a sufficiently high returns to human capital. The figure also shows the decline in average family size during the process of development. As can be seen, 

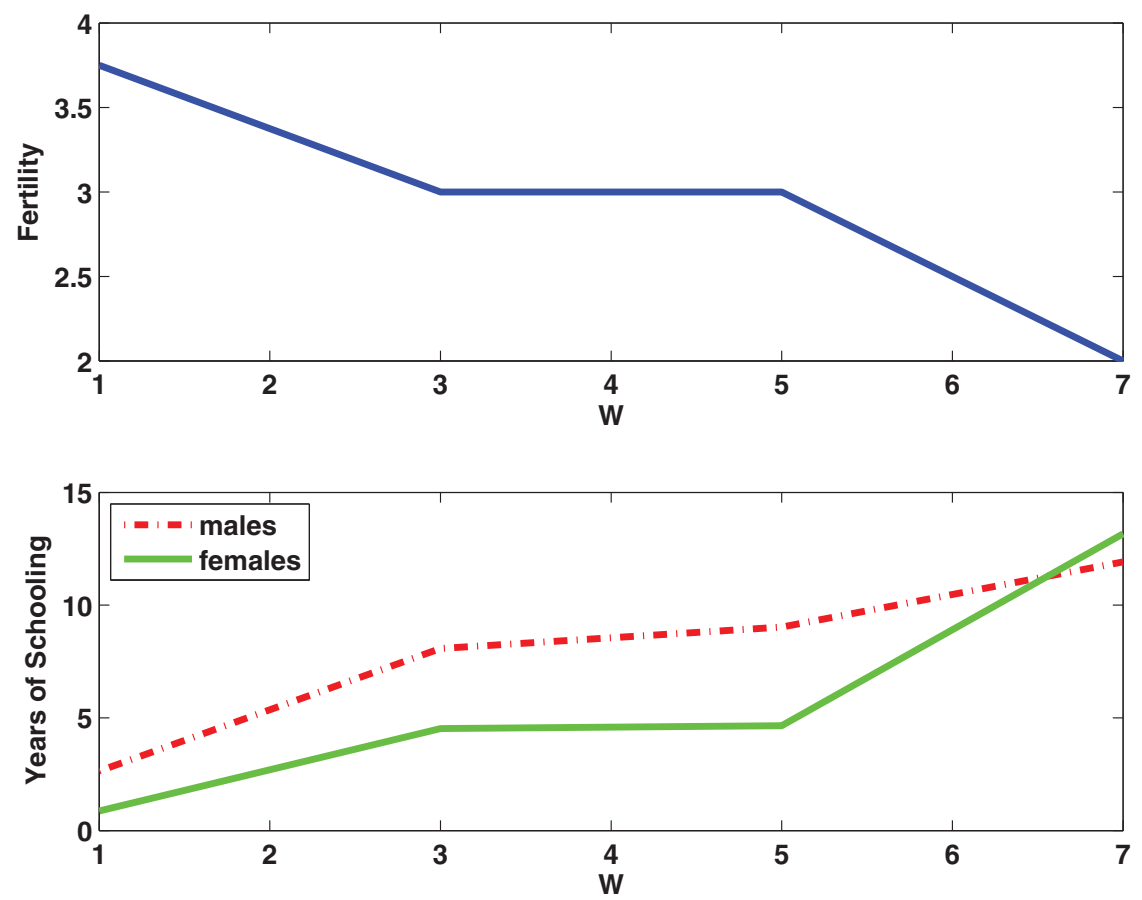

FIGURE 2. (Colour online) Equilibrium number of children and investment in the education by gender. Top panel: average fertility as a function of the returns to human capital, $w$; bottom panel: average investment in education by gender as a function of the returns to human capital, $w$. Parameter values, $\tau=0.21, b=0.5$ and $\theta=0.5$.

the increase in the returns to human capital shifts density from larger to smaller families, a process that reaches an end when all households have the same size, independently of gender composition.

The top panel of Figure 2 summarizes the fertility dynamics by showing average fertility in the economy, while the bottom panel of Figure 2 shows average education by gender. As can be seen from the figure, the increase in the returns to human capital, decreases the average family size. ${ }^{15}$ This decrease in family size, is accompanied by an increase in the average education of both females and males. ${ }^{16}$ Notice that when the returns to human capital are sufficiently low, the average education of males is higher than females. However, as family size becomes independent of the gender composition of the children, the average education of females surpasses that of males.

\section{CONCLUDING REMARKS}

In this paper, we offer a new explanation for the narrowing of the gender educational gap and its reversal. We highlight the indirect effect of the returns to human 
capital on the bias in parents' preferences for sons and the impact on the demand for children and their education. We assume that parents maximize the full income of their children and that males have an additional income, independently of their level of education. This additional income has two effects. First, it biases parental preferences toward sons. Second, it implies that females have relative advantage in producing income through education. We show that when the relative returns to human capital are sufficiently low, the bias in parents' preferences toward sons is relatively high. This implies that parents who obtain daughters in their first births end up with more children. Since daughters, on average, are born to larger families, daughters are provided with less education. As the returns to human capital increase, gender differences in producing income diminish, and, therefore, parents' bias toward sons declines. This decline reduces the variation in family size and weakens the positive correlation between family size and the number of daughters. Ultimately, when the returns to human capital are sufficiently high, the relative advantage of females in education dominates differences in family size, triggering the reversal in the gender education gap.

Our model predicts that within the household, parents provide the same level of education to both sons and daughters, independently of the returns to human capital. As we argued in the introduction, the empirical evidence on this matter in inconclusive. Our model can be extended, however, to generate a situation in which in early stages of development, sons will receive more education than their sisters, while at advanced stages of development, this gap will disappear. To see this, suppose parents maximize the expected earnings of their children, rather than their full income, and that raising children is done by mothers. When the returns to human capital are sufficiently low, fertility is sufficiently high, and mothers are expected to spend a significant part of their time raising children. This implies that females' expected earnings are significantly lower than males'. Therefore, initial differences in endowments between sons and daughters are reinforced by a differential investment in education. In contrast, when the returns to human capital are sufficiently high, fertility is sufficiently low and mothers are expected to spend (almost) as much time as their spouses in the labor market. Hence, parents do not discriminate between sons and daughters and, on average, females receive more education.

Finally, in our model, we assume that the returns to human capital are equal across the genders. Recent research, however, suggests that the returns to female's human capital is higher than for males (Becker et al. 2010). The forces of our model that generate the reversal of the gender education gap will be quantitatively but not qualitatively affected by such a modification. To see this, suppose the returns to human capital are higher for females than for males. Then, within a household, daughters will receive more education than sons. However, in early stages of development, the returns to sons' physical strength may dominate the higher returns to females' human capital, inducing parents who have sons in the first births to stop at a lower parity. This family size effect may dominate the higher returns to females' human capital. In advanced stages of development, 
family size becomes independent of the gender composition, and effects favoring higher average education for females will be reinforced.

\section{APPENDIX}

Proof of Propositions 2 and 3: Rewrite equation (11) as

$$
-\frac{1}{1-(\tau+e) n}+\frac{\theta w e^{\theta-1}}{n w e^{\theta}+n_{m} b}=0 .
$$

Assume $n$ and $n_{m}$ are continuous variables, then from implicit function theorem, we can get

$$
\frac{\partial e^{*}\left(n, n_{m}\right)}{\partial n_{m}}=\frac{-b /\left(w\left(e^{*}\left(n, n_{m}\right)\right)^{\theta-2}\right)}{2 n \theta e^{*}\left(n, n_{m}\right)+\theta(1-\theta)\left[1-\left(\tau+e^{*}\left(n, n_{m}\right)\right) n\right]}<0 .
$$

and,

$$
\frac{\partial e^{*}\left(n, n_{m}\right)}{\partial n}=\frac{-\left[\left(e^{*}\left(n, n_{m}\right)\right)^{2}+\theta e^{*}\left(n, n_{m}\right)\left(\tau+e^{*}\left(n, n_{m}\right)\right)\right]}{2 n \theta e^{*}\left(n, n_{m}\right)+\theta(1-\theta)\left[1-\left(\tau+e^{*}\left(n, n_{m}\right)\right) n\right]}<0
$$

Obviously, discreteness will not change the above result and hence the result follows.

Proof of Proposition 4: The proof of Proposition 4 proceeds in the following steps:

1. Claim 1 establishes that the utility, $V\left(n, n_{m}\right)$, is increasing in number of boys, $n_{m}$.

2. Claim 2 establishes that the utility, $V\left(n, n_{m}\right)$, is inverted $\mathrm{U}$ in the number of children, $n$, for a given number of boys, $n_{m}$.

3. Claim 3 establishes that the number of children maximizing the value function must be at least as large as the number of children maximizing the utility function for all $n_{m}$.

4. Claim 4 establishes that the number of children maximizing the utility function is non-increasing in the number of boys (if it achieves interior solution, i.e. not all children in the household are boys).

5. Claim 5 establishes that there is decreasing marginal utility of having additional child and additional boy $\left(V_{11}\left(n, n_{m}\right)<0, V_{22}\left(n, n_{m}\right)<0\right)$. Also, we claim that there is a threshold number of children, $n=\frac{1-\theta}{\tau}$, after which the marginal utility of additional child is increasing in number of boys $\left(V_{12}\left(n, n_{m}\right)>0\right)$, and the number of children, maximizing $V\left(n, n_{m}\right)$, is below $n=\frac{1-\theta}{\tau}$, where $V_{12}\left(n, n_{m}\right)<0$.

6. Finally, Claim 6 defines a function $n\left(n_{m}\right)$ as the minimum number of children such that it would not make sense to give additional birth and we prove that this $n$ is the maximizer of the value function, and thus the solution of the optimization problem.

Let $N=\left\lfloor\frac{1}{\tau}\right\rfloor$ denotes the maximal number of children where $\lfloor x\rfloor$ denotes the maximal integer smaller than $x$. Given the result in Proposition 1 that $e_{m}=e_{f}=e$, for $n_{m} \leq n \leq N$, reformulate $V\left(n, n_{m}\right)$ from equation (7) as follows:

$$
V\left(n, n_{m}\right)=\max _{e}\left\{\ln \left([1-(\tau+e) n] w H_{p}\right)+\ln \left[n w e^{\theta}+n_{m} b\right]\right\} .
$$


Recall that the value function, as defined in (6), is

$$
U\left(n, n_{m}\right)=\max \left\{V\left(n, n_{m}\right), \frac{1}{2} U\left(n+1, n_{m}\right)+\frac{1}{2} U\left(n+1, n_{m}+1\right)\right\} .
$$

If the household chooses to stop fertility at $\left(n, n_{m}\right)$, this household will get $V\left(n, n_{m}\right)$ for sure; otherwise, if it chooses to have one more child, the expected value is $\frac{1}{2} U(n+$ $\left.1, n_{m}\right)+\frac{1}{2} U\left(n+1, n_{m}+1\right)$.

We first want to introduce the following notations:

$$
\bar{n}\left(n_{m}\right)=\operatorname{argmax}_{n \geq n_{m}, n \in \mathbb{N}} V\left(n, n_{m}\right) \quad \text { and } \quad n^{*}\left(n_{m}\right)=\operatorname{argmax}_{n \geq n_{m}, n \in \mathbb{N}} U\left(n, n_{m}\right) .
$$

The analysis begins with a series of claims establishing one of the main results:

Claim 1. $V\left(n, n_{m}^{\prime}\right) \geq V\left(n, n_{m}\right)$ for $n_{m}^{\prime} \geq n_{m}$.

Proof. Suppose $V\left(n, n_{m}\right)$ is maximized when $e=e^{*}\left(n, n_{m}\right)$. Then we have

$$
V\left(n, n_{m}^{\prime}\right) \geq \ln \left(\left[1-\left(\tau+e^{*}\left(n, n_{m}\right)\right) n\right] w H_{p}\right)+\ln \left[n w\left(e^{*}\left(n, n_{m}\right)\right)^{\theta}+n_{m}^{\prime} b\right] \geq V\left(n, n_{m}\right)
$$

since $n_{m}^{\prime} \geq n_{m}$.

Claim 1 implies that $V\left(n, n_{m}\right)$ is increasing in $n_{m}$ and we will next prove that $V\left(n, n_{m}\right)$ is inverted-U shaped in $n$.

Recall that Propositions 2 and 3 show that $e^{*}\left(n, n_{m}\right)$ is strictly decreasing in $n$ and $n_{m}$. Notice that by envelope theorem, the partial derivative with respect to $n$ satisfies

$$
\begin{aligned}
\frac{\partial V\left(n, n_{m}\right)}{\partial n} & =\frac{-\left(e^{*}\left(n, n_{m}\right)+\tau\right)}{1-\left(e^{*}\left(n, n_{m}\right)+\tau\right) n}+\frac{w\left(e^{*}\left(n, n_{m}\right)\right)^{\theta}}{n w\left(e^{*}\left(n, n_{m}\right)\right)^{\theta}+n_{m} b} \\
& =\frac{\left[(1-\theta) e^{*}\left(n, n_{m}\right)-\theta \tau\right]}{\theta\left[1-\left(e^{*}\left(n, n_{m}\right)+\tau\right) n\right]} .
\end{aligned}
$$

Equation (19) is derived by plugging equation (14) into equation (18).

The partial derivative with respect to $n_{m}$ is

$$
\frac{\partial V\left(n, n_{m}\right)}{\partial n_{m}}=\frac{b}{n w\left(e^{*}\left(n, n_{m}\right)\right)^{\theta}+n_{m} b} .
$$

The partial derivative with respect to $n, \frac{\partial V\left(n, n_{m}\right)}{\partial n}$, implies that $V\left(n, n_{m}\right)$ is inverted Ushaped in $n$ :

Claim 2. $V\left(n^{\prime}, n_{m}\right)>V\left(n, n_{m}\right)$ for $\bar{n}\left(n_{m}\right) \geq n^{\prime}>n \geq n_{m}$ and $V\left(n^{\prime}, n_{m}\right)<V\left(n, n_{m}\right)$ for $\bar{n}\left(n_{m}\right) \leq n<n^{\prime}$.

Proof. Since $e^{*}$ is strictly decreasing in $n, \frac{\partial V\left(n, n_{m}\right)}{\partial n}>0$ for $n<\bar{n}\left(n_{m}\right)$ and $\frac{\partial V\left(n, n_{m}\right)}{\partial n}<0$ for $n>\bar{n}\left(n_{m}\right)$. The claim hence follows immediately.

Claims 1 and 2 imply that $n^{*}\left(n_{m}\right) \geq \bar{n}\left(n_{m}\right)$ :

Claim 3. $n^{*}\left(n_{m}\right) \geq \bar{n}\left(n_{m}\right)$ for all $n_{m}$.

Proof. Suppose not and $n^{*}\left(n_{m}\right)<\bar{n}\left(n_{m}\right)$. Then consider $V\left(n^{*}\left(n_{m}\right)+1, n_{m}\right)$. By Claim 2, it must be strictly larger than $V\left(n^{*}\left(n_{m}\right), n_{m}\right)$. Meanwhile, by Claim $1, V\left(n^{*}\left(n_{m}\right)+1, n_{m}+\right.$ 
$1) \geq V\left(n^{*}\left(n_{m}\right)+1, n_{m}\right)$. Therefore,

$$
\begin{aligned}
\frac{1}{2} U\left(n^{*}\left(n_{m}\right)+1, n_{m}\right)+\frac{1}{2} U\left(n^{*}\left(n_{m}\right)+1, n_{m}+1\right) \\
\quad \geq \frac{1}{2} V\left(n^{*}\left(n_{m}\right)+1, n_{m}\right)+\frac{1}{2} V\left(n^{*}\left(n_{m}\right)+1, n_{m}+1\right)
\end{aligned}
$$

will be strictly larger than $V\left(n^{*}\left(n_{m}\right), n_{m}\right)$, which leads to a contradiction.

The next result states that $\bar{n}\left(n_{m}\right)$ is non-increasing in $n_{m}$ if it achieves interior solution:

Claim 4. $\bar{n}\left(n_{m}\right)$ is non-increasing in $n_{m}$ if it achieves interior solution $\left(\bar{n}\left(n_{m}\right) \neq n_{m}\right)$.

Proof. First from Propositions 2 and 3 , we know $e^{*}\left(n, n_{m}\right)$ is strictly decreasing with $n_{m}$ and $n$. Given $n_{m}$, define $\hat{n}\left(n_{m}\right)=\operatorname{argmax}_{n \in \mathbb{R}} V\left(n, n_{m}\right)$. Taking the expression for $\frac{\partial V\left(n, n_{m}\right)}{\partial n}$ from equation (19) and solving $\frac{\partial V\left(n, n_{m}\right)}{\partial n}=0$, we obtain $e^{*}\left(\hat{n}\left(n_{m}\right), n_{m}\right)=\frac{\theta}{1-\theta} \tau$, which is a constant.

Notice as $n_{m}$ increases, $e^{*}\left(\hat{n}\left(n_{m}\right), n_{m}\right)$ will decrease by the previous results. Hence, $\hat{n}\left(n_{m}\right)$ must decrease to keep the equality, which implies that $\hat{n}\left(n_{m}\right)$ is strictly decreasing in $n_{m}$. If $\bar{n}\left(n_{m}\right)$ achieves an interior solution, $\bar{n}\left(n_{m}\right)$ either $\left\lfloor\hat{n}\left(n_{m}\right)\right\rfloor$ or $\left\lfloor\hat{n}\left(n_{m}\right)\right\rfloor+1$. For $n_{m}>n_{m}^{\prime}$, if $\left\lfloor\hat{n}\left(n_{m}\right)\right\rfloor<\left\lfloor\hat{n}\left(n_{m}^{\prime}\right)\right\rfloor$, it is immediate that $\bar{n}\left(n_{m}\right) \leq \bar{n}\left(n_{m}^{\prime}\right)$. The only interesting case happens when $\left\lfloor\hat{n}\left(n_{m}\right)\right\rfloor=\left\lfloor\hat{n}\left(n_{m}^{\prime}\right)\right\rfloor$ and $\bar{n}\left(n_{m}\right)=\left\lfloor\hat{n}\left(n_{m}\right)\right\rfloor+1$. We have to rule out the case that $\bar{n}\left(n_{m}^{\prime}\right)=\left\lfloor\hat{n}\left(n_{m}\right)\right\rfloor$. Suppose this is the case and hence $V\left(x+1, n_{m}^{\prime}\right) \leq V\left(x, n_{m}^{\prime}\right)$ while $V\left(x+1, n_{m}\right) \geq V\left(x, n_{m}\right)$ where $x=\left\lfloor\hat{n}\left(n_{m}\right)\right\rfloor$. Obviously, it must be the case: $V(x+$ $\left.1, n_{m}^{\prime}\right)-V\left(x+1, n_{m}\right) \leq V\left(x, n_{m}^{\prime}\right)-V\left(x, n_{m}\right)$. Notice:

$$
V\left(x+1, n_{m}\right)-V\left(x+1, n_{m}^{\prime}\right)-V\left(x, n_{m}\right)+V\left(x, n_{m}^{\prime}\right)=\int_{n_{m}^{\prime}}^{n_{m}} \int_{x}^{x+1} V_{12}\left(x_{1}, x_{2}\right) d x_{1} d x_{2} .
$$

By the intermediate value theorem, there exists $x_{1} \in[x, x+1]$ and $x_{2} \in\left[n_{m}, n_{m}^{\prime}\right]$ such that

$$
V\left(x+1, n_{m}\right)-V\left(x+1, n_{m}^{\prime}\right)-V\left(x, n_{m}\right)+V\left(x, n_{m}^{\prime}\right)=\left(n_{m}-n_{m}^{\prime}\right) V_{12}\left(x_{1}, x_{2}\right) .
$$

But the next claim implies that $V_{12}\left(x_{1}, x_{2}\right)<0$, which contradicts the previous assumption that $V\left(x+1, n_{m}^{\prime}\right)-V\left(x+1, n_{m}\right) \leq V\left(x, n_{m}^{\prime}\right)-V\left(x, n_{m}\right)$. Therefore, $\bar{n}\left(n_{m}\right)$ is non-increasing in $n_{m}$.

The above claim doesn't hold when interior solution is not achieved. In that case, $\bar{n}\left(n_{m}\right)=n_{m}$ is indeed increasing in $n_{m}$. It can be shown that interior solution can be achieved when $n_{m}$ is small and vice versa.

Claim 5. For $n>\bar{n}\left(n_{m}\right), V_{11}\left(n, n_{m}\right)<0$ and $V_{22}\left(n, n_{m}\right)<0$. $V_{12}\left(n, n_{m}\right)<0$ for $n<\frac{1-\theta}{\tau}$ but $>0$ for $n>\frac{1-\theta}{\tau}$. Moreover, $\hat{n}\left(n_{m}\right)<\frac{1-\theta}{\tau}$.

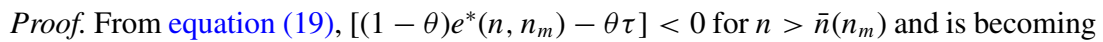
more and more negative as $n$ increases since $e^{*}$ is decreasing in $n$. Now we need to show the denominator of equation (19) is decreasing in $n$ or in other words, $\left(\tau+e^{*}\left(n, n_{m}\right)\right) n$ is increasing in $n$.

Notice by equation (16),

$$
\frac{\partial\left(\tau+e^{*}\left(n, n_{m}\right)\right) n}{\partial n}=\left(\tau+e^{*}\left(n, n_{m}\right)\right)-\frac{n\left[\left(e^{*}\left(n, n_{m}\right)\right)^{2}+\theta e^{*}\left(n, n_{m}\right)\left(\tau+e^{*}\left(n, n_{m}\right)\right)\right]}{2 n \theta e^{*}\left(n, n_{m}\right)+\theta(1-\theta)\left[1-\left(\tau+e^{*}\left(n, n_{m}\right)\right) n\right]},
$$


which can be simplified to

$$
\begin{aligned}
& \frac{\left[\theta e^{*}\left(n, n_{m}\right)\left(\theta \tau-(1-\theta) e^{*}\left(n, n_{m}\right)\right)+\left(\tau+e^{*}\left(n, n_{m}\right)\right) \theta(1-\theta)\left[1-\left(\tau+e^{*}\left(n, n_{m}\right)\right) n\right]\right]}{2 n \theta e^{*}\left(n, n_{m}\right)+\theta(1-\theta)\left[1-\left(\tau+e^{*}\left(n, n_{m}\right)\right) n\right]} \\
& \quad>0,
\end{aligned}
$$

for $n>\bar{n}\left(n_{m}\right)$. Since the numerator is becoming more and more negative and its denominator is decreasing in $n$, we get $V_{1}\left(n, n_{m}\right)$ is decreasing in $n$ and hence $V_{11}\left(n, n_{m}\right)<0$.

For $V_{22}$, we need to show $n w\left(e^{*}\left(n, n_{m}\right)\right)^{\theta}+n_{m} b$ is increasing in $n_{m}$. By equation (15),

$$
\frac{\partial\left(n w\left(e^{*}\left(n, n_{m}\right)\right)^{\theta}+n_{m} b\right)}{\partial n_{m}}=\frac{b\left[n \theta e^{*}\left(n, n_{m}\right)+\theta(1-\theta)\left[1-\left(\tau+e^{*}\left(n, n_{m}\right)\right) n\right]\right]}{2 n \theta e^{*}\left(n, n_{m}\right)+\theta(1-\theta)\left[1-\left(\tau+e^{*}\left(n, n_{m}\right)\right) n\right]}>0 .
$$

Therefore, $V_{2}\left(n, n_{m}\right)$ is decreasing in $n_{m}$ and hence $V_{22}\left(n, n_{m}\right)<0$.

From equation (19), $V_{1}\left(n, n_{m}\right)$ is increasing in $e^{*}\left(n, n_{m}\right)$ when $n<\frac{1-\theta}{\tau}$ and decreasing in $e^{*}\left(n, n_{m}\right)$ for $n>\frac{1-\theta}{\tau}$. Since $e^{*}\left(n, n_{m}\right)$ is decreasing in $n_{m}, V_{12}\left(n, n_{m}\right)^{\tau}<0$ for $n<\frac{1-\theta}{\tau}$ but $>0$ for $n>\frac{1-\theta}{\tau}$.

Notice the first order condition of equation (14) implies that

$$
n e^{*}\left(n, n_{m}\right) \leq \frac{\theta(1-\tau n)}{1+\theta},
$$

and at $\hat{n}\left(n_{m}\right), e^{*}\left(n, n_{m}\right)=\frac{\theta \tau}{1-\theta}$ and hence:

$$
\hat{n}\left(n_{m}\right) \frac{\theta \tau}{1-\theta} \leq \frac{\theta(1-\tau n)}{1+\theta} \Longrightarrow \hat{n}\left(n_{m}\right)<\frac{1-\theta}{\tau} .
$$

We are ready to characterize $n^{*}\left(n_{m}\right)$. The main result is:

\section{Claim 6. Define}

$$
n\left(n_{m}\right)=\min \left\{n \geq n_{m}: V\left(n, n_{m}\right) \geq \frac{1}{2} V\left(n+1, n_{m}\right)+\frac{1}{2} V\left(n+1, n_{m}+1\right)\right\}
$$

and if there doesn't exist $n$ such that $V\left(n, n_{m}\right) \geq \frac{1}{2} V\left(n+1, n_{m}\right)+\frac{1}{2} V\left(n+1, n_{m}+1\right)$, just let $n\left(n_{m}\right)=N$. If

$$
F\left(n, n_{m}\right)=V\left(n, n_{m}\right)-\frac{1}{2} V\left(n+1, n_{m}\right)-\frac{1}{2} V\left(n+1, n_{m}+1\right)
$$

is increasing in $n$ and for a given $n_{m} n\left(n_{m}\right)<\frac{1-\theta}{\tau}$, then we should have $n\left(n_{m}\right)$ is nonincreasing in $n_{m}$ and $n^{*}\left(n_{m}\right)=n\left(n_{m}\right)$.

Proof. Obviously, it cannot be the case that $n^{*}\left(n_{m}\right)<n\left(n_{m}\right)$. Secondly, $n\left(n_{m}\right)$ must be larger than $\bar{n}\left(n_{m}\right)$ by Claim 2. Define

$$
F\left(n, n_{m}\right)=V\left(n, n_{m}\right)-\frac{1}{2} V\left(n+1, n_{m}\right)-\frac{1}{2} V\left(n+1, n_{m}+1\right) .
$$

Since $F\left(n, n_{m}\right)<0$ for $n<\bar{n}\left(n_{m}\right)$ and $F\left(n, n_{m}\right) \geq 0$ at $n=n\left(n_{m}\right)$, by continuity, there must exist a unique $\tilde{n}\left(n_{m}\right) \in\left[\bar{n}\left(n_{m}\right), n\left(n_{m}\right)\right]$ such that $F\left(\tilde{n}\left(n_{m}\right), n_{m}\right)=0$ and $n\left(n_{m}\right)=$ $\left\lceil\tilde{n}\left(n_{m}\right)\right\rceil$ when $n\left(n_{m}\right)$ achieves the interior solution. Here, $\lceil x\rceil$ is the smallest integer larger than $x$. 
$F$ is increasing implies: if $F\left(n, n_{m}\right)=0$ has a solution, that solution must be unique. By the implicit function theorem,

$$
\tilde{n}^{\prime}\left(n_{m}\right)=-\frac{\partial F / \partial n_{m}}{\partial F / \partial n}
$$

where

$$
\frac{\partial F}{\partial n_{m}}=V_{2}\left(n, n_{m}\right)-\frac{1}{2} V_{2}\left(n+1, n_{m}\right)-\frac{1}{2} V_{2}\left(n+1, n_{m}+1\right) .
$$

For $n\left(n_{m}\right)<\frac{1-\theta}{\tau}, V_{12}<0$ and hence $V_{2}\left(n, n_{m}\right)>V_{2}\left(n+1, n_{m}\right)$. Meanwhile, Claim 5 implies that $V_{2}\left(n+1, n_{m}+1\right)<V_{2}\left(n+1, n_{m}\right)$. Therefore, $\frac{\partial F}{\partial n_{m}}>0$ and $\tilde{n}^{\prime}\left(n_{m}\right)<0$.

Suppose $n^{*}\left(n_{m}\right)>n\left(n_{m}\right)$ for some $n_{m}$, which cannot happen when $n\left(n_{m}\right)=N . n\left(n_{m}\right)<$ $N$ implies that $n\left(n_{m}\right)=\left\lceil\tilde{n}\left(n_{m}\right)\right\rceil$. From the fact that $\tilde{n}\left(n_{m}\right)$ is decreasing in $n_{m}$, we know $n\left(n_{m}\right)$ is non-increasing in $n_{m}$. Therefore, if $V\left(n, n_{m}\right) \geq \frac{1}{2} V\left(n+1, n_{m}\right)+\frac{1}{2} V\left(n+1, n_{m}+\right.$ $1)$, it must be the case that $V\left(\hat{n}, n_{m}+1\right)>\frac{1}{2} V\left(\hat{n}+1, n_{m}+1\right)+\frac{1}{2} V\left(\hat{n}+1, n_{m}+2\right)$ for all $\hat{n} \geq n+1$.

Notice $n^{*}\left(n_{m}\right)>n\left(n_{m}\right)$ implies that $n^{*}\left(n_{m}+1\right)>n\left(n_{m}\right)+1$. Suppose not. Then, $n^{*}\left(n_{m}+1\right) \leq n\left(n_{m}\right)+1$ implies that the household will stop having one more child once $n_{m}+1$ is reached. Suppose $n^{*}\left(n_{m}\right)=n\left(n_{m}\right)+t$ for some integer $t>0$. Then the strategy associated with $n^{*}\left(n_{m}\right)$ will generate expected value:

$$
\left.\hat{U}\left(n\left(n_{m}\right), n_{m}\right)\right|_{n^{*}\left(n_{m}\right)}=\sum_{s=1}^{t} \frac{1}{2^{s}} V\left(n\left(n_{m}\right)+s, n_{m}+1\right)+\frac{1}{2^{t}} V\left(n\left(n_{m}\right)+t, n_{m}\right) .
$$

The definition of $n\left(n_{m}\right)$ implies $V\left(n\left(n_{m}\right)+s-1, n_{m}\right)>\frac{1}{2} V\left(n\left(n_{m}\right)+s, n_{m}\right)+$ $\frac{1}{2} V\left(n\left(n_{m}\right)+s, n_{m}+1\right)$ for any $1<s \leq t$ and thus

$$
\begin{aligned}
\left.\hat{U}\left(n\left(n_{m}\right), n_{m}\right)\right|_{n^{*}\left(n_{m}\right)} & <\sum_{s=1}^{t-1} \frac{1}{2^{s}} V\left(n\left(n_{m}\right)+s, n_{m}+1\right)+\frac{1}{2^{t-1}} V\left(n\left(n_{m}\right)+t-1, n_{m}\right) \\
& <\sum_{s=1}^{t-2} \frac{1}{2^{s}} V\left(n\left(n_{m}\right)+s, n_{m}+1\right)+\frac{1}{2^{t-2}} V\left(n\left(n_{m}\right)+t-1, n_{m}\right) \cdots \\
& <\frac{1}{2} V\left(n\left(n_{m}\right)+1, n_{m}\right)+\frac{1}{2} V\left(n\left(n_{m}\right)+1, n_{m}+1\right) \leq V\left(n\left(n_{m}\right), n_{m}\right) .
\end{aligned}
$$

Obviously, such $n^{*}\left(n_{m}\right)>n\left(n_{m}\right)$ cannot be optimal. The only way to allow $n^{*}\left(n_{m}\right)>n\left(n_{m}\right)$ is to have $n^{*}\left(n_{m}+1\right)>n\left(n_{m}\right)+1$, which implies $n^{*}\left(n_{m}+1\right)>n\left(n_{m}\right)+$ $1>n\left(n_{m}+1\right)$. Apply similar arguments and we should have: $n^{*}\left(n_{m}+2\right)>n\left(n_{m}\right)+2>$ $n\left(n_{m}+2\right)$. Repeat the above process and eventually, we can get to some $\hat{n}_{m}$ such that $n^{*}\left(\hat{n}_{m}\right)>N$ which is impossible.

Finally we can conclude that $n^{*}\left(n_{m}\right)=n\left(n_{m}\right)$.

Proof of Proposition 5: We begin by showing that when $b=0, n$ is independent of $n_{m}$. We then show that the case where $b=0$ is equivalent to the case where $w \rightarrow \infty$.

When $b=0$, sons and daughters are identical and the value function only depends on the total number of children $n$ :

$$
U\left(n, n_{m} ; b=0\right)=U(n)=\max _{n} V(n)
$$


where

$$
V(n)=\max _{e}\left\{\ln \left([1-(\tau+e) n] w H_{p}\right)+\ln \left[n w e^{\theta}\right]\right\} .
$$

The difficulty is that $n$ is discrete but we can first treat it as if it were a continuous variable. Then by envelope theorem, the optimal choice of number of children $\hat{n}^{*}$ should satisfy:

$$
U^{\prime}(n)=-\frac{\left(\tau+e^{*}(n)\right)}{1-\left(\tau+e^{*}(n)\right) n}+\frac{1}{n}=0 .
$$

Meanwhile, first order condition implies that $e^{*}(n)$ should satisfy:

$$
-\frac{n}{1-\left(\tau+e^{*}(n)\right) n}+\frac{\theta}{e^{*}(n)}=0 .
$$

Equations (22) and (23) imply that $\hat{n}^{*}$ should satisfy:

$$
e^{*}\left(\hat{n}^{*}\right)=\frac{\theta \tau}{1-\theta} \quad \text { and } \quad \hat{n}^{*}=\frac{1-\theta}{2 \tau} .
$$

Since the actual optimal choice $n^{*}$ should be an integer, it must be the one closest to $\hat{n}^{*}$. Equation (24) shows that $n^{*}$ is independent of $n_{m}$ and $w$.

Since $U\left(n, n_{m}\right)$ is continuous in $b, \frac{\partial n^{*}\left(n_{m}\right)}{\partial n_{m}} \rightarrow 0$ as $b \rightarrow 0$ for any constant $w^{\prime}$. Let $w \equiv D w^{\prime}$ and $b \equiv D b^{\prime}$, where $D \in \mathbb{R}$. Notice that the maximization problem

$$
V\left(n, n_{m}\right)=\max _{e}\left\{\ln \left([1-(\tau+e) n] w H_{p}\right)+\ln \left[n w e^{\theta}+n_{m} b\right]\right\}
$$

can be written as

$$
\begin{aligned}
V\left(n, n_{m}\right) & =\max _{e}\left\{\ln \left([1-(\tau+e) n] w H_{p}\right)+\ln \left[n D w^{\prime} e^{\theta}+n_{m} D b^{\prime}\right]\right\} \\
& =\max _{e}\left\{\ln \left([1-(\tau+e) n] w H_{p}\right)+\ln \left[n w^{\prime} e^{\theta}+n_{m} b^{\prime}\right]+\ln (D)\right\} .
\end{aligned}
$$

Finally, notice that $w \rightarrow \infty$ implies that $b^{\prime} \rightarrow 0$.

\section{NOTES}

1 See for example, Galor and Weil (2000), Galor and Moav (2002), Greenwood and Seshadri (2002), and Doepke (2004). For the review of this literature see Galor (2011).

2 Echevarria and Merlo (1999) and Doepke and Tertilt (2009) model gender differences in education and fertility choice. They assume that each household contains the same number of boys and girls. As will become clear below, the uncertainty regarding the sex composition of children within the household is crucial in our model. Furthermore, they do not provide an explanation for the reversal of the gender education gap.

3 These statements are taken from the fact sheet on Goal 3, "Promote Gender Equality and Empower Women", prepared for the United Nations Summit, 20-22 September 2010, New York. See http://www.un.org/millenniumgoals/pdf/MDG_FS_3_EN.pdf.

4 Our model assumes the existence of a quantity-quality tradeoff and postulates the same preferences as in Galor and Weil (2000), Hazan and Berdugo (2002), de la Croix and Doepke (2003), Moav (2005) and Hazan and Zoabi (2006). The majority of the empirical literature on the quantity-quality tradeoff (Rosenzweig and Wolpin 1980; Black, Devereux and Salvanes 2005; Jensen 2005; Angrist, 
Lavy and Schlosser 2010) looks at shocks to quantity, due to either twins or sibling sex composition and studies its impact on quality. The evidence is inconclusive. In our model, parents substitute quality for quantity when the returns to human capital, i.e. the rental rate on one unit of human capital, increase. Interestingly, Bleakley and Lange (2009) study the eradication of the hookworm disease in the American South, which has increased the returns to human capital and found significant reduction in fertility and increase in the investment in human capital in response to the increase in the returns to human capital.

5 Technically, our model resembles that of Doepke (2005) in that both models feature sequential fertility as well as uncertainty. However, in Doepke's paper the uncertainty is related to the survival probability of the children.

6 This framework is consistent with Becker and Tomes (1976) who assumed that offspring do not have equal endowments. These differences can emerge through ability, public support, luck and other factors. Here, the additional income can be interpreted in several ways. First, one can interpret this additional income as a return to the absolute advantage males have in innate physical strength. Galor and Weil (1996) and Sauré and Zoabi (2014) modeled these differences in endowments by assuming that nature endows males and females equal "brain", but endows males more "brawn" than females. Their latter assumption is supported by research in the medical literature showing that men are stronger than women and that the source of this difference is at least partially due to biological differences. For example, Round, Jones, Honour and Nvill (1999) found that testosterone is important in explaining differences in strength between the sexes. Second, one can think that this additional income is due to differential investment in physical strength. Suppose that in addition to investment in education, parents also invest in physical strength. Further, suppose that parents can choose to provide a fixed amount of investment, say nutrition, for which males obtain the return $b$ while females would obtain the return $b^{\prime}$. If the cost of investment is sufficiently small and the difference between $b$ and $b^{\prime}$ is sufficiently large our results would hold. Nevertheless, the model is not robust to the various formulations of the gender gap. For example, a percent-wise modeling of male's extra income will not work.

7 Notice that this is a possibility in our framework because fertility is discrete. Thus, even though girls are only "asymptotically equal" to boys, all households are of the exact same size.

8 Bacolod and Blum (2010) show that physical strength is required in only $8 \%$ of the occupations of college graduates; in $27 \%$ of high school graduates jobs and in $46 \%$ of jobs occupied by workers without a high school degree.

9 See also Hu and Schlosser (2011).

10 Angrist and Evans (1998) find evidence consistent with preferences for sex-variety in offspring. This feature is absent from our theory.

11 The somewhat broader question of equal or different treatment for boys and girls has been investigated and delivers different results. For example, Barcellos, Carvalho and Lleras-Muney (2014) documented that in India, boys receive on average 10\% more parental time than girls, and they are also more likely to be breastfed for longer and be given vaccinations and vitamin supplements.

12 Assuming that raising children requires a combination of parents time and output as in Hazan and Zoabi (2014) will not alter the qualitative results of the model.

13 Households' consumption is the only choice variable that is affected by the level of human capital of each adult, but this variable is irrelevant to the dynamics we highlight in the paper.

14 Our model abstracts from the marriage market. Incorporating the marriage market into our model will diverge the focus from our mechanism.

15 In the real world each child has two parents, while in our model each child has one parent. Hence we multiplied average fertility by two.

16 Average education is presented as average years of schooling. This is calculated by multiplying the fraction of parents' time allocated to children's education by the length of adults' life, which is assumed to be fifty years. 


\section{REFERENCES}

Angrist, Joshua D. and William N. Evans (1998) Children and their parents labor supply: Evidence from exogenous variation in family size. American Economic Review 88(3), 450-477.

Angrist, Joshua D., Victor Lavy and Analia Schlosser (2010) Multiple experiments for the causal link between the quantity and quality of children. Journal of Labor Economics 28, 773-823.

Bacolod, Marigee P. and Bernardo S. Blum (2010) Two sides of the same coin: U.S. residual? Inequality and the gender gap. Journal of Human Resources, 2010 45(1), 197-242.

Barcellos, Silvia Helena, Leandro Carvalho, and Adriana Lleras-Muney (2014) Child gender and parental investments in India: Are boys and girls treated differently? American Economic Journal: Applied Economics 6(1), 157-89.

Basu, Kaushik (2006) Gender and say: A model of household behaviour with endogenously determined balance of power. Economic Journal 116(511), 558-580.

Becker, Gary S. and Gregg H. Lewis (1973) On the interaction between the quantity and quality of children. Journal of Political Economy 81, S279-S288.

Becker, Gary S. and Nigel Tomes (1976) Child endowments and the quantity and quality of children. Journal of Political Economy 84(4, Part 2), S143-S162.

Becker, Gary S., William H. J. Hubbard and Kevin M. Murphy (2010) Explaining the worldwide boom in higher education of women, Journal of Human Capital 4(3), 203-241.

Ben-Porath, Yoram and Finis Welch (1976) Do sex preferences really matter? Quarterly Journal of Economics 90(2), 285-307.

Black, Sandra E., Paul J. Devereux and Kjell G. Salvanes (2005) The more the merrier? The effect of family composition on children's education. Quarterly Journal of Economics 120(2), 669-700.

Bleakley, Hoyt and Fabian Lange (2009) Chronic disease burden and the interaction of education, fertility, and growth. The Review of Economics and Statistics 91(1), 52-65.

Butcher, Kristin F. and Anne Case (1994) The effect of sibling sex composition on womens education and earnings. Quarterly Journal of Economics 109, 531-563.

Chiappori, Pierre-Andre and Yoram Weiss (2007) Divorce, remarriage and child support. Journal of Labor Economics. 25, 37-74.

Chiappori, Pierre-Andre, Murat Iyigun and Yoram Weiss (2009) Investment in schooling and the marriage market. American Economic Review 99, 1689-1713.

de la Croix, David and Matthias Doepke (2003) Inequality and gorwth: Why differential fertility matters. American Economic Review 93(4), 1091-1113.

Doepke, Matthias (2004) Accounting for fertility decline during the transition to growth. Journal of Economic Growth 9(3), 347-383.

Doepke, Matthias (2005) Child mortality and fertility decline: Does the Barro-Becker model fit the facts?. Journal of Population Economics 18(2), 337-366.

Doepke, Matthias and Michéle Tertilt (2009) Women's liberation: What's in it for men? Quarterly Journal of Economics 124(4), 1541-1591.

Doepke, Matthias and Michéle Tertilt (2011) Does female empowerment promote economic development? Unpublished Manuscript.

Duflo, Esther (2011) Women's Empowerment and Economic Development. NBER Working Paper 17702.

Echevarria, Cristina and Antonio Merlo (1999) Gender differences in education in a dynamic household bargaining model. International Economic Review 40, 265-286.

Galor, Oded (2005) From stagnation to growth: Unified growth theory. In P. Aghion and S. N. Durlauf (eds.), Handbook of Economic Growth, vol. 1A, pp. 171-293. Amsterdam: Elsevier.

Galor, Oded (2011) Unified Growth Theory. New Jersey: Princeton University Press.

Galor, Oded and David N. Weil (1996) The gender gap, fertility, and growth. American Economic Review 86(3), 374-387.

Galor, Oded and David N. Weil (2000) Population, technology, and growth: From malthusian stagnation to the demographic transition and beyond. American Economic Review 90(4), 806-828. 
Galor, Oded and Omer Moav (2002) Natural selection and the origin of economic growth. Quarterly Journal of Economics 117(4), 1113-1191.

Goldin, Claudia (1990) Understanding the Gender Gap: An Economic History of American Women. New York: Oxford University Press.

Goldin, Claudia and Lawrence F. Katz (2002) The power of the pill: Oral contraceptives and women's career and marriage decisions. Journal of Political Economy 110(4), 730-770.

Goldin, Claudia, Lawrence Katz, and Ilyana Kuziemko (2006) The homecoming of American college women: A reversal of the college gender gap. Journal of Economic Perspectives 20(4), 133-156.

Greenwood, Jeremy and Ananth Seshadri (2002) The U.S. demographic transition. American Economic Review 92(2), 153-159.

Haider, Steven J. and Kathleen M. McGarry (2012) Parental Investments in College and Later Cash Transfers. NBER Working Paper No. 18485.

Hazan, Moshe and Binyamin Berdugo (2002) Child labor, fertility, and economic growth. Economic Journal 112(482), 810-828.

Hazan, Moshe and Hosny Zoabi (2006) Does longevity cause growth? A theoretical critique. Journal of Economic Growth 11(4), 363-376.

Hazan, Moshe and Hosny Zoabi (2014) Do highly educated women choose smaller families? Economic Journal. doi: 10.1111/ecoj.12148.

Hu, Luojia and Analia Schlosser (2011) Prenatal sex selection and girls' well-being: Evidence from India. Unpublished manuscript.

Iyigun, Murat and Randall P. Walsh (2007) Building the family nest: pre-marital investments, marriage markets and spousal allocations. Review of Economic Studies 74(2), 507-535.

Jensen, Robert (2005) Equal treatment, unequal outcomes? Generating sex inequalities through fertility behavior. Unpublished Manuscript, Harvard University.

Jones, Larry E. and Michèle Tertilt (2008) An economic history of fertility in the U.S.: 1826-1960. In P. Rupert (ed.), Frontiers of Family Economics, pp. 165-230. Boston, MA: Emerald.

Kaestner, Robert (1997) Are brothers really better? Sibling sex composition and educational attainment revisited. Journal of Human Resources 32, 250-284.

Moav, Omer (2005) Cheap children and the persistence of poverty. Economic Journal 115(500), $88-110$.

Pitt, Mark M., Mark R. Rosenzweig and Nazmul Hassan (2012) Human capital investment and the gender division of labor in a brawn-based economy. American Economic Review 102(7), 3531-3560.

Rendall, Michelle (2010) Brain versus Brawn: The Realization of Women's Comparative Advantage. The University of Zurich, mimeo.

Rosenzweig, Mark R. and Kenneth I. Wolpin (1980) Testing the quantity-quality fertility model: The use of twins as a natural experiment. Econometrica 48, 227-240.

Round, J. M., D. A. Jones, J. W. Honour and A. M. Nvill (1999) Hormonal factors in the development of differences in strength between boys and girls during adolescence: A longitudinal study. Annals of Human Biology 26(1), 49-62.

Sauré, Philip and Hosny Zoabi (2014) International trade, the gender wage gap and female labor force participation. Journal of Development Economics 111, 17-33.

Thomas, Duncan and John Strauss (1997) Health and wages: Evidence on men and women in Urban Brazil. Journal of Econometrics 77(1), 159-185. 